\title{
Detection of Human Papillomavirus 33 in Erosive Oral Lichen Planus
}

\author{
Sareh Farhadi (iD ${ }^{1}$, Donia Sadri (iD) ${ }^{1}$, Mojgan Bandehpour (iD ${ }^{2}$, Mana Akbari (iD) ${ }^{3}$, Elnaz Jafarzadeh (iD) ${ }^{3}$ and \\ Mehrdad Hashemi (iD) ${ }^{4, *}$ \\ ${ }^{1}$ Department of Oral and Maxillofacial Pathology, Faculty of Dentistry, Tehran Medical Sciences, Islamic Azad University, Tehran, Iran \\ ${ }^{2}$ Cellular and Molecular Biology Research Center, Shahid Beheshti University of Medical Sciences, Tehran, Iran \\ ${ }^{3}$ Dentist, Tehran, Iran \\ ${ }^{4}$ Department of Genetics, Faculty of Advanced Sciences and Technology, Tehran Medical Sciences, Islamic Azad University, Tehran, Iran \\ "Corresponding author: Department of Genetics, Faculty of Advanced Sciences and Technology, Tehran Medical Sciences, Tehran Islamic Azad University, Tehran, Iran. Email: \\ drmehashemi@gmail.com
}

Received 2020 February 10; Revised 2020 August 19; Accepted 2020 August 31.

\begin{abstract}
Background: A correlation is suggested between oral lichen planus (OLP) and the human papillomavirus (HPV) with possible malignant transformation potential in OLP.

Objectives: The present study aimed at evaluating the prevalence of HPV-16 and HPV-18 as the most recognized oncogenic subtypes and relatively recently introduced subtype HPV33 in OLP samples.

Methods: This retrospective study was carried out on 32 OLP samples (consisting of 12 reticular and 20 erosive forms) and 20 healthy oral mucosa samples. Polymerase chain reaction (PCR) was undertaken to identify HPV Deoxyribonucleic Acid (DNA). Subsequently, the samples positive for HPV DNA underwent PCR analysis again with the specific primers. The data were analyzed statistically by Fisher's exact test regarding the significance level of lower than 0.05 .

Results: Eight out of 32 OLP samples (25\%) and none of the 20 normal mucosa samples (0\%) exhibited HPV DNA. The presence of HPV in the OLP group was significantly higher than that in the normal mucosa $(\mathrm{P}=0.014)$. Also, all the samples that exhibited HPV DNA were registered as the erosive form. Besides, one sample (3.12\%) exhibited the 873-bp band, which was attributed to HPV-18, and 7 samples (21.87\%) exhibited the 300-bp band, which was attributed to HPV-33.

Conclusions: Based on the recent findings in the current study of the Iranian population, the presence of high-risk HPV subtypes, whether primarily or as a secondary infection, can suggest the malignant transformation potential for the studied OLP samples. The exclusive presence of these subtypes in the erosive type of this lesion and the noticeable presence of HPV-33 might reflect this issue's importance. However, further studies are necessary to evaluate the possibility of a higher proliferation rate of HPV in erosive lichen planus and identify its possible malignant transformation mechanism.
\end{abstract}

Keywords: Human Papillomavirus 18, Human Papillomavirus 33, Lichen Planus, Oral

\section{Background}

Oral lichen planus (OLP) is a chronic disorder that affects the oral mucosa and the skin, reproductive system, scalp, and nails. The worldwide prevalence of OLP in adult patients is noticeable with a reported rate of $1.08 \%$ to $2.3 \%$ $(1,2)$. This variability has been reported to be much higher in the Iranian population with a range of $0.7 \%$ to $76.9 \%$ (3, 4).

Clinically, OLP might appear in different forms, including reticular, plaque, erosive, atrophic, papular, and bullous forms $(5,6)$. The specific pathogenicity of this lesion is still unknown. In scientific sources, it has been recognized as an inflammatory and autoimmune lesion (7). One of the critical points about OLP is its malignant potential, especially in the erosive form. In some studies, the malig- nant risk of OLP has been reported at $1.2 \%$ to 3.2\% in 10-year follow-ups, especially in the erosive form (8). Although these lesions are classified as oral potentially malignant disorders (OPMDs) $(9,10)$, the indirect role of other factors in the induction of malignant transformation of OLP is possible, as well.

Questions on the malignant potential of lichen planus are still unanswered. As early as 1987, the association between human papillomavirus (HPV) and OLP was introduced (11). HPV comprises a large group of viruses with double-stranded deoxyribonucleic acid (DNA) and belongs to the Papillomaviridae family. HPV has a predilection for squamous epithelium and might infect the skin or mucosa. More than 130 types of HPV have been identified, with $>30$ types of which specifically affecting the oral mucosa. 
HPV might be associated with various benign, premalignant, and malignant epithelial lesions and the majority of the affected individuals are asymptomatic and do not exhibit any clinical symptoms. (12) Unlike a higher rate of HPV infections, malignant changes induced by HPV are relatively rare and might be induced by some oncogenic subtypes of this virus. HPV-16 and HPV-18 were the most recognized ones in this argument. However, the other related subtypes, such as HPV-33, were presented recently for their possible effect on malignant progression $(13,14)$.

Many researchers have studied the pathogenesis of HPV in OLP lesions and reported different findings of the prevalence of this virus and its subtypes in this lesion (1524 ). In one study published before 1998, 107 OLP samples were studied, $23 \%$ of which were HPV-positive. Besides, 1929 normal oral mucosa samples were tested for HPV DNA, and $11 \%$ were positive (25). The first 3 most prevalent HPV types were HPV-6, -11, and -16, in which the last one (HPV-16) has been reported to be a significant risk for oropharyngeal cancers and oral cavity malignancies (26). However, the results have been conflicting, as some studies show that HPV plays a vital role in the pathogenesis of OLP and its malignant transformation (18, 23, 27-32). Based on these studies, the correlation between HPV and OLP is still consistently noticeable.

\section{Objectives}

Therefore the present study was undertaken to evaluate the prevalence of HPV-16 and HPV-18 as the most recognized oncogenic subtypes and relatively recently introduced subtype HP-V33 in OLP samples.

\section{Methods}

\subsection{Sample Selection}

This retrospective study was conducted on 32 paraffin blocks with definite histopathological diagnosis of OLP based on "modified World Health Organization (WHO) criteria" (33). The samples were obtained from the archives of the Department of Oral and Maxillofacial Pathology, Faculty of Dentistry, Tehran Medical Sciences, Islamic Azad University. Based on the Institutional Ethics Committee approval (code: IR.IAU.DENTAL.REC.1395,1), 20 normal mucosa paraffin blocks were also included. The samples were re-evaluated by two oral pathologists, and the histopathologic diagnosis was re-confirmed, using microscopic sections with hematoxylin-eosin staining. The normal mucosa samples were obtained from non-pathological oral surgical procedures such as the application of dental implants or extraction of the third molar teeth. All the samples were placed in a similar age group. Also, none of the samples had a history of HPV-related pathological lesions, such as squamous papilloma and warts. The selected samples were re-evaluated by an oral pathologist, and after meeting the scientific criteria and the quality of the tissue, 8 sections with $10 \mu \mathrm{m}$ thickness for each one were prepared from the middle portion of every paraffin block sample.

The samples were, then, transferred to the Laboratory of the Cellular and Molecular Biology Research Center, Faculty of Medicine, Shahid Beheshti University of Medical Sciences, Tehran, Iran.

\subsection{DNA Extraction and Primer Design}

In the next stage, to identify HPV virus in the paraffin samples, firstly, the DNA of the whole tissue was extracted with the use of QIAamp DNA FFPE Tissue Kit (QIAGEN, USA) and after its confirmation with electrophoresis, polymerase chain reaction (PCR) was applied for 18S rDNA gene.

For HPV detection, firstly, the specific general primers of HPV were designed, with the capacity to identify all the virus subtypes. Samples positive for HPV were confirmed by PCR, using specific primers and Amplicon PCR Master Mix (Ampliqon, Denmark).

PCR was applied with the use of the designed primers by considering the alignment of more than 10 sequences from HPV proteins containing E1, E2, E4, E5, E6, E7, L1, and L2 in 35 HPV genotypes. Human Building Computer Interaction (HBCI) and National Center for Biotechnology Information (NCBI) databases were used to determine the sequences of HPV (NCBI Reference Sequence: NC-001526.4) (34). Comparisons were made, using the Clustal W server, and the following primers were designed to identify different subtypes of HPV (Table 1).

\begin{tabular}{|c|c|c|}
\hline Type of Virus & $\begin{array}{c}\text { PCR Fragment, } \\
\text { bp }\end{array}$ & Primer Sequences $\left(5^{\prime}-3^{\prime}\right)$ \\
\hline \multirow{2}{*}{ HPV 18} & \multirow{2}{*}{873} & F: TGCCGCCACGTCTAATGTTT \\
\hline & & R: CACCAAAGTTCCAATCCTCTA \\
\hline \multirow{2}{*}{ HPV 16} & \multirow{2}{*}{550} & F: AAACTAAGGGCGTAACCG \\
\hline & & R: CAGGACACAGTGGCTTTTG \\
\hline \multirow{2}{*}{ HPV 33} & \multirow{2}{*}{300} & F: GAGGTATATGATTTTGCATTTG \\
\hline & & R: CCCTGCCCAACGACCCGAAAT \\
\hline \multirow{2}{*}{ HPV 11} & \multirow{2}{*}{446} & F: GGCCAGCAGCACGTCCG \\
\hline & & R: CATCTTCTCCTTCATAGAC \\
\hline
\end{tabular}

Abbreviatons: HPV, human papillomavirus; PCR, polymerase chain reaction. 


\subsection{HPV Detection by Multiplex (PCR)}

The primers used were prepared in a mix for application in multiplex PCR. The optimal annealing temperature for PCR was considered $52^{\circ} \mathrm{C}$, and the proliferated products were loaded on a $2 \%$ agar gel agarose and compared with the molecular weight marker. The product of the samples containing the relevant band was used as a pattern and reproliferated, using specific primers to make sure of the accuracy of the band.

The PCR was carried out in Eppendorf gradient equipment, consisting of one cycle for 5 minutes at $90^{\circ} \mathrm{C}$ for initial denaturation. Totally, 40 cycles were carried out for 30 seconds at $94^{\circ} \mathrm{C}$ for denaturation, 60 seconds at $52^{\circ} \mathrm{C}$ for annealing, 60 seconds at $72^{\circ} \mathrm{C}$ for the extension, and one cycle at $72^{\circ} \mathrm{C}$ for the final extension.

The procedure consisted of 30 reactions. The volume and concentration of the material used for the procedure were as follows: Master mix $\left(15 \mu, \mathrm{X}^{1}\right)$, primers $(2 \mu, \mathrm{pmol})$, DNA ( $1 \mu \mathrm{L}, 100 \mathrm{ng})$, and DW (12 $\mu \mathrm{L}$, up to $30 \mu \mathrm{L})$. After the application of PCR and determination of the positive cases, the sequences of the segments extracted were determined for definitive confirmation.

\subsection{Statistical Analysis}

The data were analyzed, using Fisher's exact test at a significance level of $\mathrm{P}<0.05$.

\section{Results}

\subsection{Demographic Findings}

The evaluated samples consisted of 32 OLP (12 reticular and 20 erosive types); $67.3 \%$ and $32.7 \%$ belonged to females and males, respectively, with a mean age of $43.8 \pm$ 2.78 years. Also, 23 of 32 OLP samples were obtained from the buccal mucosa, with 9 from the gingiva, whereas, all the normal samples were from the gingiva.

\subsection{HPV Detection}

Also, 8 of 32 OLP samples (25\%) and none of the 20 normal mucous samples (0\%) contained HPV DNA. The results showed a significantly higher rate of HPV in OLP than normal mucous samples $(\mathrm{P}=0.014)$. The samples containing HPV DNA belonged to females (62.5\%) and males (37.5\%). Also, all the samples containing HPV DNA were of the erosive form of OLP, and all of them were obtained from the buccal mucosa.

Among the samples containing HPV's DNA, 7 samples contained a 300-bp band attributed to HPV-33 and one contained an 850-bp band attributed to HPV-18 (Figure 1 and Table 2).

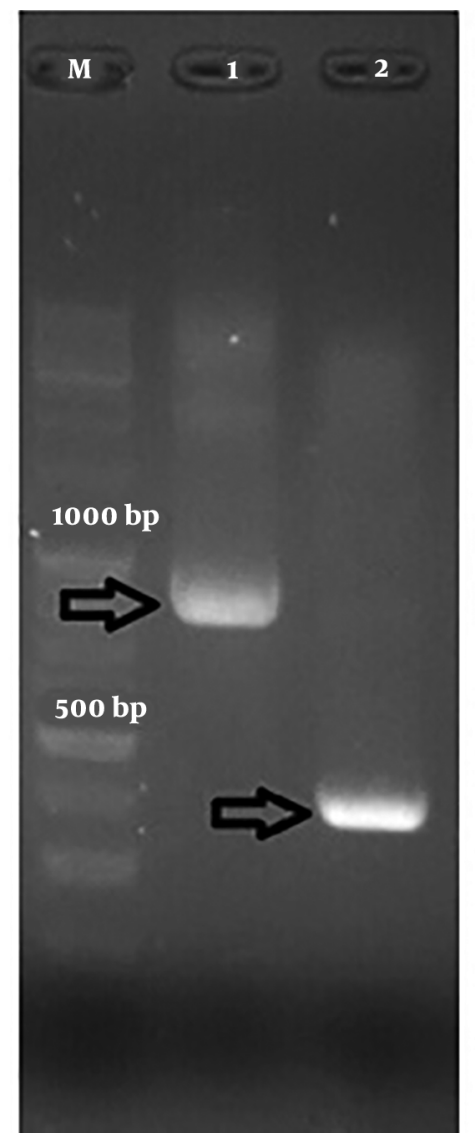

Figure 1. HPV fragment PCR product. Lane M, 100 bp DNA ladder, lane 1, 850 bp product for HPV18; lane 2, 300 bp product for HPV33.

Figures 1 and 2 show the results of the PCR of the samples in the present study. The PCR products were confirmed by sequencing.

\section{Discussion}

As early as 1987, the correlation between HPV and OLP was reported (11), but many studies were conducted after presenting different prevalence rates of HPV in this lesion. In this field, the findings of the present study, indicating the presence of $25 \%$ of HPV DNA, might be comparable to the results of some other studies (15-22), which reported an HPV incidence rate of $15.4 \%$ to $42.6 \%$ for OLP and $0 \%$ to $7 \%$ for normal mucosa samples. However, lower incidence rates of $0.02 \%$ and $0.32 \%$ were also reported by Arirachakaran et al. (35) and Szarka et al. (36), respectively. In addition to the possible explanation of different findings mentioned earlier, different sampling methods and variations of technical procedures could be mentioned. 


\begin{tabular}{|c|c|c|c|c|c|c|c|}
\hline Number & Age & Sex & OLP Type & Location & HPV Detection & $\begin{array}{l}\text { The Length of The Segments Resulting from } \\
\text { PCR Reaction, bp }\end{array}$ & Genome Attributed to HPV Subtype \\
\hline 1 & 62 & M & $\mathrm{E}$ & B & & & \\
\hline 2 & 57 & $\mathrm{~F}$ & E & B & & & \\
\hline 3 & 31 & M & $\mathrm{H}$ & B & & & \\
\hline 4 & 45 & $\mathrm{~F}$ & $\mathrm{E}$ & B & + & 300 & HPV-33 \\
\hline 5 & 52 & $\mathrm{~F}$ & $\mathrm{H}$ & B & & & \\
\hline 6 & 76 & $\mathrm{~F}$ & E & G & & & \\
\hline 7 & 29 & M & $\mathrm{H}$ & B & & & \\
\hline 8 & 55 & $\mathrm{~F}$ & $\mathrm{E}$ & G & & & \\
\hline 9 & 55 & $\mathrm{~F}$ & $\mathrm{H}$ & B & & & \\
\hline 10 & 50 & $\mathrm{~F}$ & $\mathrm{H}$ & B & & & \\
\hline 11 & 40 & $\mathrm{~F}$ & $\mathrm{H}$ & B & & & \\
\hline 12 & 59 & M & $\mathrm{E}$ & B & & & \\
\hline 13 & 35 & $\mathrm{~F}$ & $\mathrm{H}$ & G & & & \\
\hline 14 & 80 & $\mathrm{~F}$ & $\mathrm{E}$ & B & & & \\
\hline 15 & 36 & $\mathrm{~F}$ & $\mathrm{E}$ & B & & & \\
\hline 16 & 33 & M & $\mathrm{E}$ & B & + & 800 & HPV-18 \\
\hline 17 & 57 & M & $\mathrm{H}$ & G & & & \\
\hline 18 & 48 & $\mathrm{~F}$ & $\mathrm{E}$ & B & + & 300 & HPV-33 \\
\hline 19 & 44 & M & $\mathrm{E}$ & G & & & \\
\hline 20 & 58 & M & H & G & & & \\
\hline 21 & 41 & $\mathrm{~F}$ & $\mathrm{E}$ & B & & & \\
\hline 22 & 62 & M & $\mathrm{E}$ & B & + & 300 & HPV-33 \\
\hline 23 & 51 & M & $\mathrm{E}$ & B & + & & \\
\hline 24 & 59 & $\mathrm{~F}$ & H & G & & & \\
\hline 25 & 49 & $\mathrm{~F}$ & $\mathrm{H}$ & G & & & \\
\hline 26 & 45 & F & E & B & + & 300 & HPV-33 \\
\hline 27 & 37 & $\mathrm{~F}$ & $\mathrm{E}$ & B & & & \\
\hline 28 & 61 & F & $\mathrm{E}$ & G & & & \\
\hline 29 & 61 & $\mathrm{~F}$ & $\mathrm{E}$ & B & & & \\
\hline 30 & 65 & M & $\mathrm{H}$ & B & & & \\
\hline 31 & 61 & $\mathrm{~F}$ & $\mathrm{E}$ & в & + & 300 & HPV-33 \\
\hline 32 & 70 & F & E & B & + & 300 & HPV-33 \\
\hline
\end{tabular}

Abbreviatons: B, buccal mucosa; E, erosive oral lichen planus; F, female; h, hyperkeratotic Oral Lichen planus; G, gingiva; HPV, human papillomavirus; M, Male.

The calculation of OR would help better explain HPV prevalence in OLP samples; the calculated numeric value shows the risk of exposure to HPV contamination for the studied samples compared to normal mucosal samples. In this field, the OR ranged from 2.43 to 132.04 in the scientific reports related to different geographic populations (37).

Concerning the association between malignant changes of OLP and HPV, Szarka et al. (36) and Gorsky et al. (38) reported that the high-risk subtypes HPV-16 and HPV-18 might be a risk factor for malignant changes of OLP. Recently, Debanth et al. (28) and Feher et al. (39) reported the presence of HPV-33 in OLP samples in line with the present study. The present finding was consistent with other studies; it was reported that the higher potential 


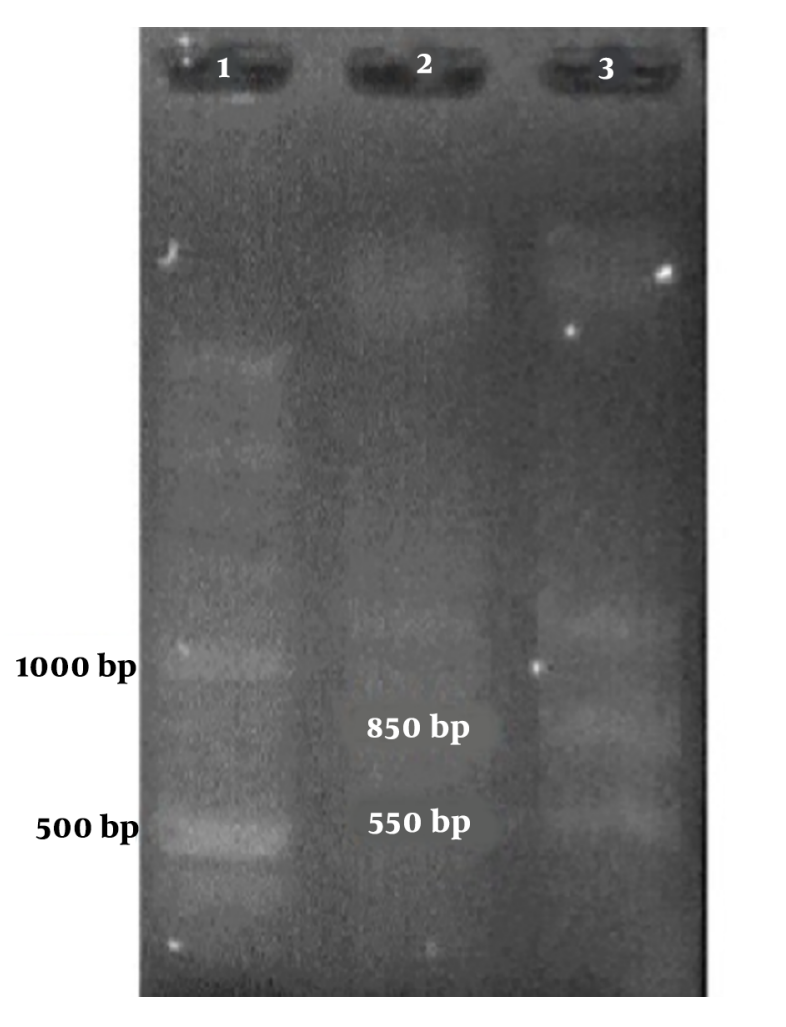

Figure 2. The PCR product of positive control in agarose gel electrophoresis.

of changes leading to malignancy in oral erosive lichen planus could be attributed to the presence of high-risk HPV subtypes $(35,40)$. However, comparing the given subtypes, our findings would be comparable to studies conducted by O. flatharta et al. (15) and Campisi et al. (16), with a report of the most frequent subtypes, i.e., HPV-16 and HPV-33. However, in studies carried out by Kato et al. (17) and Vasper et al. (18), in addition to subtypes 16 and 33, other subtypes, including subtypes 31 and 18, were detected.

Furthermore, Jontell et al. (19) showed the presence of HPV-6 and HPV-16 in the erosive form of OLP; Sahebjamiee et al. (20) detected subtypes of HPV-16 and HPV18 , and Siribang-on (22) reported that the most frequent subtypes were 16,18 , and 33 . The existing results are consistent with the present findings. The sensitivity of the PCR technique, the sampling method, inclusion and exclusion criteria, type of OLP, sample location, and ethnicity might explain the differences between the results of different studies. Also, the findings of HPV-33 in the studied Iranian population are consistent with other reports. However, its higher rate in the present study, compared to previous studies, might be justified.

Besides, another interesting finding of the present study is that all the samples containing HPV DNA were registered as the erosive form of OLP. The etiology of OLP is not clear yet; however, it is generally accepted as a $\mathrm{T}$ cellmediated inflammatory disease (8). The reaction of these specific $\mathrm{CD}^{+} \mathrm{T}$ cells is similar to what occurs during viral infections (41). Therefore, viral involvement seems to be possible in the pathogenicity of OLP. On the other hand, it has been reported that HPV can influence the proliferation of epithelium by affecting the basal cells and penetration through the corneum layer, breached due to mucosal or cutaneous injury to reach the basal cells in the basal cell layer. Once the basal cells are contaminated with HPV, the viral particles are incorporated into them as a part of the normal cell cycle, proliferating along with these cells and remaining inside to differentiate into the spinous layer cells. When the contaminated cells reach the granular tissue, they approach their final differentiation, and HPV rapidly increases in number, from a few to thousands, and the mature viruses are released into the spinous layer $(42,43)$.

Regarding the above consideration, it might be assumed that HPV can easily invade the cells in the OLP lesion through the injured mucous area and infect it. In this context, Nishimura et al. (44) reported that HPV might be detected in the oral mucosa of patients with subsequent epithelial erosion, and the erosive mucosa might be the etiologic factor for such contamination. However, since all the samples contaminated with HPV in the present study were erosive lichen planus samples, this hypothesis might be supported that HPV could contaminate the lichen planus lesions secondarily through the injured oral mucosa. However, Viguier et al. (40) suggested that HPV infection exhibits a function consistent with the proliferation of TCD8 cells; therefore, inflammation in OLP can have a possible role in the direct induction of HPV genome proliferation.

Also, as another explanation, it has been reported that the use of topical steroids, which is common in the treatment of OLP and increasing the oxidative stress in ulcerative mucosa, can decrease immunity and activates HPV. This finding indicates that mucosal ulceration or erosion in OLP and frequent use of steroids in the treatment of OLP might lead to HPV infection (7). Besides, since in the present study, samples with a history of topical steroid use were not excluded, it might be possible to attribute the reciprocal effect between HPV proliferation and atrophic epithelium in erosive OLP samples to the use of topical steroids.

In a comprehensive evaluation, the presence of highrisk HPV subtypes in OLP, either primarily or secondarily, might lead to the alteration and transformation of the oral mucosa, which can be crucial. However, more evaluation is recommended for a better explanation. 


\subsection{Conclusions}

Based on the recent findings of this study on an Iranian population, the presence of high-risk HPV subtypes might suggest the malignant transformation potential for the studied OLP samples. Also, the exclusive presence of these subtypes in the erosive type of this lesion and notable presence of HPV-33, whether primarily or as a secondary infection, might increase the importance of this result. However, further studies might be needed to evaluate the possibility of a higher proliferation of HPV in erosive lichen planus and identify its probable mechanism of malignant transformation.

\section{Supplementary Material}

Supplementary material(s) is available here [To read supplementary materials, please refer to the journal website and open PDF/HTML].

\section{Footnotes}

Authors' Contribution: SF and MH developed the original idea and the protocol, abstracted and analyzed data, wrote the manuscript, and is a guarantor. DS, MB, MA, and EJ contributed to the development of the protocol, abstracted data, and prepared the manuscript.

Conflict of Interests: The authors claim that, they have no conflict of interest for this research.

Ethical Approval: The ethical approval code was IR.IAU.DENTAL.REC.1395,1.

Funding/Support: Tehran Medical Sciences, Faculty of Dentistry, Islamic Azad University funded this research.

\section{References}

1. Kansky AA, Didanovic V, Dovsak T, Brzak BL, Pelivan I, Terlevic D. Epidemiology of oral mucosal lesions in Slovenia. Radiol Oncol. 2018;52(3):263-6. doi: 10.2478/raon-2018-0031. [PubMed: 30210036]. [PubMed Central: PMC6137360].

2. Kovac-Kovacic M, Skaleric U. The prevalence of oral mucosal lesions in a population in Ljubljana, Slovenia. J Oral Pathol Med. 2000;29(7):3315. doi: 10.1034/j.1600-0714.2000.290707.x. [PubMed:10947249].

3. Shahsavari F, Sadri D, Jolehar M, Farzanehnejad R. Epidemiologic study of the prevalence of oral mucosal lesions in the biopsied samples at buali and imam khomeini hospitals from 2000 to 2014. J Res Dent Maxillofoc Sci. 2016;1(1):28-33. doi: 10.29252/jrdms.1.1.28.

4. Pakfetrat A, Javadzadeh-Bolouri A, Basir-Shabestari S, Falaki F. Oral Lichen Planus: a retrospective study of 420 Iranian patients. Med Oral Patol Oral Cir Bucal. 2009;14(7):E315-8. [PubMed: 19300365].

5. Rad M, Hashemipoor MA, Mojtahedi A, Zarei MR, Chamani G, Kakoei S, et al. Correlation between clinical and histopathologic diagnoses of oral lichen planus based on modified WHO diagnostic criteria. Oral Surg Oral Med Oral Pathol Oral Radiol Endod. 2009;107(6):796-800. doi: 10.1016/j.tripleo.2009.02.020. [PubMed:19464654].
6. Kamath VV, Setlur K, Yerlagudda K. Oral lichenoid lesions - a review and update. Indian J Dermatol. 2015;60(1):102. doi: 10.4103/00195154.147830. [PubMed: 25657414]. [PubMed Central: PMC4318020]

7. Acay RR, Felizzola CR, de Araujo N, de Sousa SO. Evaluation of proliferative potential in oral lichen planus and oral lichenoid lesions using immunohistochemical expression of p53 and Ki67. Oral Oncol. 2006;42(5):475-80. doi: 10.1016/j.oraloncology.2005.09.012. [PubMed: 16364678].

8. Epstein JB, Wan LS, Gorsky M, Zhang L. Oral lichen planus: progress in understanding its malignant potential and the implications for clinical management. Oral Surg Oral Med Oral Pathol Oral Radiol Endod. 2003;96(1):32-7. doi: 10.1016/s1079-2104(03)00161-6. [PubMed: 12847441].

9. Al-Hashimi I, Schifter M, Lockhart PB, Wray D, Brennan M, Migliorati $\mathrm{CA}$, et al. Oral lichen planus and oral lichenoid lesions: diagnostic and therapeutic considerations. Oral Surg Oral Med Oral Pathol Oral Radiol Endod. 2007;103 Suppl:S25 e1-12. doi: 10.1016/j.tripleo.2006.11.001. [PubMed: 17261375].

10. Warnakulasuriya S, Johnson NW, van der Waal I. Nomenclature and classification of potentially malignant disorders of the oral mucosa. J Oral Pathol Med. 2007;36(10):575-80. doi: 10.1111/j.16000714.2007.00582.x. [PubMed: 17944749].

11. Maitland NJ, Cox MF, Lynas C, Prime SS, Meanwell CA, Scully C. Detection of human papillomavirus DNA in biopsies of human oral tissue. Br J Cancer. 1987;56(3):245-50. doi: 10.1038/bjc.1987.185. [PubMed: 2822070]. [PubMed Central: PMC2002211].

12. Pytynia KB, Dahlstrom KR, Sturgis EM. Epidemiology of HPVassociated oropharyngeal cancer. Oral Oncol. 2014;50(5):380-6. doi: 10.1016/j.oraloncology.2013.12.019. [PubMed: 24461628]. [PubMed Central: PMC4444216].

13. de Villiers EM, Gunst K. Characterization of seven novel human papillomavirus types isolated from cutaneous tissue, but also present in mucosal lesions. J Gen Virol. 2009;90(Pt 8):1999-2004. doi: 10.1099/vir.0.011478-0. [PubMed: 19386784].

14. Syrjanen S, Lodi G, von Bultzingslowen I, Aliko A, Arduino P, Campisi $G$, et al. Human papillomaviruses in oral carcinoma and oral potentially malignant disorders: a systematic review. Oral Dis. 2011;17 Suppl 1:58-72. doi: 10.1111/j.1601-0825.2011.01792.x. [PubMed: 21382139].

15. O. Flatharta C, Flint SR, Toner M, Butler D, Mabruk MJ. Investigation into a possible association between oral lichen planus, the human herpesviruses, and the human papillomaviruses. Mol Diagn. 2003;7(2):73-83. doi: 10.1007/BF03260023. [PubMed:14580227].

16. Campisi G, Giovannelli L, Arico P, Lama A, Di Liberto C, Ammatuna $P$, et al. HPV DNA in clinically different variants of oral leukoplakia and lichen planus. Oral Surg Oral Med Oral Pathol Oral Radiol Endod. 2004;98(6):705-11. doi: 10.1016/j.tripleo.2004.04.012. [PubMed: 15583544].

17. Kato S, Kawai R, Isomura M, Sato N, Yoshida W, Kamiya K, et al. Human papillomavirus in oral lichen planus of Japanese patients. J Hard Tissue Biol. 2015;24(2):181-8. doi: 10.2485/jhtb.24.181.

18. Vesper M, Riethdorf S, Christoph E, Ruthke A, Schmelzle R, Loning T. [Detection of human papillomavirus (HVP)-DNA in oral manifestation of lichen planus]. Mund Kiefer Gesichtschir. 1997;1(3):146-9. German. doi: 10.1007/BF03043534. [PubMed: 9410622].

19. Jontell M, Watts S, Wallstrom M, Levin L, Sloberg K. Human papilloma virus in erosive oral lichen planus. J Oral Pathol Med.1990;19(6):273-7. doi: 10.1111/j.1600-0714.1990.tb00841.x. [PubMed: 2169530].

20. Sahebjamiee M, Sand L, Karimi S, Biettolahi JM, Jabalameli F, Jalouli J. Prevalence of human papillomavirus in oral lichen planus in an Iranian cohort. J Oral Maxillofac Pathol. 2015;19(2):170-4. doi: 10.4103/0973-029X.164528. [PubMed: 26604492]. [PubMed Central: PMC4611924].

21. Razavi SM, Ghalayani P, Salehi MR, Attarzadeh H, Shahmoradi M. Human papilloma virus as a possible factor in the pathogenesis of oral lichen planus. Dent Res J (Isfahan). 2009;6(2):82-6. [PubMed: 21528036]. [PubMed Central: PMC3075460]. 
22. Khovidhunkit SO, Buajeeb W, Sanguansin S, Poomsawat S, Weerapradist W. Detection of human papillomavirus in oral squamous cell carcinoma, leukoplakia and lichen planus in Thai patients. Asian Pac J Cancer Prev. 2008;9(4):771-5. [PubMed:19256774].

23. Liu T, Zhang H, Yang X, Li X, Shi Y, Niu W, et al. Study on expression of p16 and human papillomavirus 16 and 18 (E6) in OLP and its malignant transformation. Pathol Res Pract. 2018;214(2):296-302. doi: 10.1016/j.prp.2017.09.014. [PubMed: 29254790].

24. Mattila R, Rautava J, Syrjanen S. Human papillomavirus in ora atrophic lichen planus lesions. Oral Oncol. 2012;48(10):980-4. doi: 10.1016/j.oraloncology.2012.04.009. [PubMed: 22658678]

25. Rautava J, Syrjanen S. Human papillomavirus infections in the oral mucosa. J Am Dent Assoc. 2011;142(8):905-14. doi: 10.14219/jada.archive.2011.0297. [PubMed: 21804057].

26. de Villiers EM, Fauquet C, Broker TR, Bernard HU, zur Hausen H. Classification of papillomaviruses. Virology. 2004;324(1):17-27. doi 10.1016/j.virol.2004.03.033. [PubMed: 15183049].

27. Boyd AS, Annarella M, Rapini RP, Adler-Storthz K, Duvic M. Falsepositive polymerase chain reaction results for human papillomavirus in lichen planus. Potential laboratory pitfalls of this procedure. J Am Acad Dermatol. 1996;35(1):42-6. doi: 10.1016/S01909622(96)90494-6. [PubMed: 8682962].

28. Debanth S, Singh PA, Mehrotra R, Singh M, Gupta SC, Pandya S, et al. Human papillomavirus infection and premalignant lesions of the oral cavity: A cross-sectional study in Allahabad, North India. Asia Pac JClin Oncol. 2009;5(2):111-8. doi:10.1111/j.1743-7563.2009.01200.x.

29. Pol CA, Ghige SK, Gosavi SR. Role of human papilloma virus-16 in the pathogenesis of oral lichen planus-an immunohistochemical study. Int Dent J. 2015;65(1):11-4. doi: 10.1111/idj.12125. [PubMed: 25256345].

30. Cox M, Maitland N, Scully C. Human herpes simplex-1 and papillomavirus type 16 homologous DNA sequences in normal, potentially malignant and malignant oral mucosa. Eur J Cancer B Oral Oncol. 1993;29B(3):215-9. doi: 10.1016/0964-1955(93)90025-a. [PubMed: 8298425].

31. Cianfriglia F, Di Gregorio DA, Cianfriglia C, Marandino F, Perrone Donnorso R, Vocaturo A. Incidence of human papillomavirus infection in oral leukoplakia. Indications for a viral aetiology. J Exp Clin Cancer Res. 2006;25(1):21-8. [PubMed: 16761614].

32. Giovannelli L, Campisi G, Colella G, Capra G, Di Liberto C, Caleca MP, et al. Brushing of oral mucosa for diagnosis of HPV infection in patients with potentially malignant and malignant oral lesions. Mol Diagn Ther. 2006;10(1):49-55. doi: 10.1007/BF03256442. [PubMed: 16646577].

33. van der Meij EH, van der Waal I. Lack of clinicopathologic correlation in the diagnosis of oral lichen planus based on the presently available diagnostic criteria and suggestions for modifications. JOral Pathol Med. 2003;32(9):507-12. doi: 10.1034/j.1600-0714.2003.00125.x.
[PubMed: 12969224].

34. NCBI Reference Sequence: NC_001526.4. NCBI; 2018. Available from: https://www.ncbi.nlm.nih.gov/nuccore/NC_001526.

35. Arirachakaran P, Chansaengroj J, Lurchachaiwong W, Kanjanabud $\mathrm{P}$, Thongprasom K, Poovorawan Y. Oral lichen planus in thai patients has a low prevalence of human papillomavirus. ISRN Dent. 2013;2013:362750. doi: 10.1155/2013/362750. [PubMed: 23762572]. [PubMed Central: PMC3677628]

36. Szarka K, Tar I, Feher E, Gall T, Kis A, Toth ED, et al. Progressive increase of human papillomavirus carriage rates in potentially malignant and malignant oral disorders with increasing malignant potential. Oral Microbiol Immunol. 2009;24(4):314-8. doi: 10.1111/j.1399302X.2009.00516.x. [PubMed: 19572894].

37. Ma J, Zhang J, Zhang Y, Lv T, Liu J. The Magnitude of the Association between Human Papillomavirus and Oral Lichen Planus: A Meta-Analysis. PLoS One. 2016;11(8). e0161339. doi: 10.1371/journal.pone.0161339. [PubMed: 27571417]. [PubMed Central: PMC5003373].

38. Gorsky M, Epstein JB. Oral lichen planus: malignant transformation and human papilloma virus: a review of potential clinical implications. Oral Surg Oral Med Oral Pathol Oral Radiol Endod. 2011;111(4):4614. doi:10.1016/j.tripleo.2010.11.007. [PubMed: 21330164].

39. Feher E, Gall T, Murvai M, Kis A, Boda R, Sapy T, et al. Investigation of the occurrence of torque tenovirus in malignant and potentially malignant disorders associated with human papillomavirus. J Med Virol. 2009;81(11):1975-81. doi: 10.1002/jmv.21627. [PubMed: 19774682].

40. Viguier M, Bachelez H, Poirier B, Kagan J, Battistella M, Aubin F, et al. Peripheral and local human papillomavirus 16-specific CD8+ T-cell expansions characterize erosive oral lichen planus. J Invest Dermatol. 2015;135(2):418-24. doi: 10.1038/jid.2014.397. [PubMed: 25207820].

41. Abbas AK, Lichtman AH, Pillai S. Chap 6. Cellular and molecular immunology. 9th ed. Netherland: Elsevier Health Sciences; 2017.

42. Kajitani N, Satsuka A, Kawate A, Sakai H. Productive lifecycle of human papillomaviruses that depends upon squamous epithelial differentiation. Front Microbiol. 2012;3:152. doi:10.3389/fmicb.2012.00152. [PubMed: 22536200]. [PubMed Central: PMC3334820].

43. Narisawa-Saito M, Kiyono T. Basic mechanisms of high-risk human papillomavirus-induced carcinogenesis: roles of E6 and E7 proteins. Cancer Sci. 2007;98(10):1505-11. doi: 10.1111/j.1349-7006.2007.00546.x. [PubMed: 17645777].

44. Nishimura Y, Maeda H, Hattori M, Azumaya F, Muramatsu I, Kameyama Y, et al. [Human papillomavirus infection in the oral cavity of denture wearers]. Nihon Hotetsu Shika Gakkai Zasshi. 2004;48(5):713-22. Japanese. doi: 10.2186/jjps.48.713. [PubMed: 15818004]. 